\title{
The Abnormal Population Growth and Urban Sprawl of an Arabian Gulf City: The Case of Abu Dhabi City
}

\author{
Fayez M. Elessawy \\ Geography and Urban Sustainability Department, College of Humanities \& Social Sciences, Alexandria \& United Arab Emirates \\ Universities, Al Ain, United Arab Emirates \\ Email: f.elessawy@uaeu.ac.ae
}

How to cite this paper: Elessawy, F. M. (2021). The Abnormal Population Growth and Urban Sprawl of an Arabian Gulf City: The Case of Abu Dhabi City. Open Journal of Social Sciences, 9, 245-269. https://doi.org/10.4236/jss.2021.92017

Received: January 13, 2021

Accepted: February 17, 2021

Published: February 20, 2021

Copyright (c) 2021 by author(s) and Scientific Research Publishing Inc. This work is licensed under the Creative Commons Attribution International License (CC BY 4.0).

http://creativecommons.org/licenses/by/4.0/

\begin{abstract}
Abu Dhabi is the capital city of the United Arab Emirates. The capital went through a radical transformation from a nomadic settlement before the 70's of the $20^{\text {th }}$ century to a metropolis that ranked as the world's fourth favorite city in 2013. It became "the safest city in the world" for the fourth time in January 2020. Abu Dhabi and other Arabian Gulf cities have evolved rapidly in the second half of the $20^{\text {th }}$ century, due to investment of oil and gas revenues. Abu Dhabi's population has been growing significantly at an average annual rate of $5.2 \%$ during the last two decades. To this end, the total population of the city has grown rapidly by $1000 \%$ over the last 42 years. According to the first census conducted in 1975, the total population of Abu Dhabi was 120,000 inhabitants, which increased in 2019 to more than 1.3 million. This increase makes Abu Dhabi's population one of the fastest growing cities in the world in terms of annual population growth rate. Abu Dhabi city is a good example of a rapidly developing city. Until 1969 the city was characterized by its slow-growth economy. Its population lived in traditional houses made of palm fronds with poor infrastructure. The rapid development of the city transformed Abu Dhabi from a small poor and isolated fishing village into a global financial and leisure center. Its built-up area increased from only 54 square kilometers in 1975 to 758 square kilometers in 2019 . This rapid spread (1300\% in 44 years) makes the city one of the fastest growing cities in the world. The researcher applied the topical approach with the use of analytical and cartographic techniques to reach the aims of the study to understand the issue of population growth and its effect on urban sprawl in Abu Dhabi city during the period 1960 to 2019 which has been fuelled by economic growth and technological advancements.
\end{abstract}

\section{Keywords}

Abu Dhabi, Population Growth, Expatriates Guest Workers, Abnormal Urban 
Growth, Global Business Hub

\section{Introduction}

The United Arab Emirates is marked today by the extraordinary changes brought about by urbanization. According to 2018 estimates by the United Nations, most of its population (87\%) are living in urban centers. Comparing it with other developing countries, it is found that this rate of urbanization is one of the highest in the world (United Nations, 2019). The urban expansion that has occurred in most of the seven Emirates' urban centers is shown not only in the spectacular growth of the major cities particularly Dubai, Abu Dhabi and Sharjah, but also in the rapid development of medium-sized towns such as $\mathrm{Al}$ Ain, Ras El Khaimah, Ajman and El Fujairah.

Abu Dhabi city has evolved rapidly in the seventies of the 20th century, due to investment of oil and gas revenues. The fast-economic growth resulted in the extensive jump in urbanization. Since 1971 in the aftermath of the establishment of the United Arab Emirates with Abu Dhabi as its capital city, it has been receiving large numbers of expatriate and migrant guest workers whose presence has dramatically changed the geography of the emerging state. The need for expatriate and migrant guest workers coincided with the recent economic boom, which was fuelled by immense oil revenues. The government invested in colossal projects aimed at building the country's infrastructure. Consequently, Abu Dhabi and other large urban centres in the United Arab Emirates witnessed a great boom in population and in urban development which continue unabated.

The size of population of Abu Dhabi city was very small up until 1975. The majority of the population including the citizens were engaged in fishing and trading activities. But the total population has grown by nearly $1000 \%$ over the last 40 years. Whereas in 1975 the total population was 120,000 inhabitants, it has increased to more than 1.323 million in 2019. This increase makes Abu Dhabi population as one of the fastest growing cities in the world in terms of annual population growth rate. In a related context, expatriate and immigrant guest workers have contributed profoundly to this population growth since they constitute approximately $90 \%$ of the total population. Such expatriates originate from many different countries but mostly from Asia and the Arab world. Asians, constitute at least $65 \%$ of the total population. A small percentage of expatriates originate from Europe and the United States. Foreign labourers are engaged in all fields of works. Furthermore, they play a very significant role in the development of the city (Elessawy, 2020).

Abu Dhabi city is a clear case of a rapidly developing city. From 1975 to till present the urban area has expanded enormously, and the rapid development of the city has transformed it from a small fishing village into a global business, financial and leisure hub. During the last two decades, Abu Dhabi city's built-up 
area expanded like never before. The economic growth accelerated and so did the level of investment. This resulted in more planned development projects to support the urban sprawl of the city and to change deserts into modern urban neighbourhoods (Allawi, 2017). The total built-up area has increased from only 13 square Kilometres in 1975 to 758 square kilometres in 2019. And that implies that Abu Dhabi's urbanised land area increased by $1700 \%$ in only 44 years (Elessawy, 2020). This astonishing rate of growth makes the city one of the fastest growing in the world. (In brief, Abu Dhabi has undergone significant urban change and population growth over the past decades, which transformed it from a small desert trading centre to a global business hub and an economic centre.

The main objective of this study is to provide a better understanding of the issue of population growth and its effect on urban sprawl in Abu Dhabi city which has been fuelled by economic growth and technological advancements. In other words, how a small fishing village became a global business centre and tourist hub. The researcher applied the topical approach with the use of analytical and cartographic techniques to reach the aims: The rapid population growth and the abnormal urban sprawl.

\section{Rapid Population Growth of Abu Dhabi City}

Lack of clarity and scarcity of data during the period prior to 1975 is the main problem facing any study on population of United Arab Emirates. Most of the data relies on estimates. The first accurate demonstrative population census was conducted in 1975, with additional surveys carried out during the 80's and 90's and the most recent one is the 2005 census (Elessawy, 2020). Based on the different observations of the statistic figures and derivations, it was clearly notable that until the 1960's the population size of Abu Dhabi was insignificant and people were mainly recognized by basic professions, where most of of them were involved in little agriculture, rural handicraft, herding, fishing, pearl collecting and trade as sources of income. With the harsh climate and scarcity of water and other resources, the population was as small as 16,000 in 1960 compared to 1.3 million at present. Oil wealth has transformed the economy of Abu Dhabi dramatically. It enabled the country to move from a subsistence state to a modern high-income country. During the same period, the role of expatriate and migrant guest workers started to appear. At the same time the population began to increase to 32,000 by 1965 and to reach 120,000 in 1975 (Figure 1). For that reason, this period was described as the stage of "small population size".

Following the economic and social development during the past decades, exceptional population growth has been observed. After the discovery and the increase in oil prices, the government of Abu Dhabi realised substantial new revenue streams which stimulated the confidence of the government as well as the resolve to build out the civic infrastructure of the emirate. Such investment into the economy as well as the political stability in the emirate encouraged blue chip companies, large contractors and foreign domestic investors interested in joint ventures with the government to establish their presence in the emirate as well as 
invest. Economic policies rendered the emirate as practically tax-free for companies were considered one of the most attractive reasons to establish a presence in Abu Dhabi. Consequently, many guest workers were needed to meet the need of the infrastructure boom and the construction of projects for development since the nationals were not skilled enough for the required projects (Elessawy, 2014). Most of the foreign labour forces were of Asian origin.

Since the end of 1973, substantial oil revenues helped the government to invest in economic and social infrastructure and to boost economic activities in general. Private investment, specifically, led to substantial urbanization which resulted in a $1000 \%$ increase in population from 1975 to 2019. Data in Table 1 and Figure 1 indicate that Abu Dhabi's population increased from 120,000 in 1975 to 1.32 million in 2019. This period of the first decade of the new millennium could be described as a truly substantial period of growth for Abu Dhabi as the population grew from 655,000 in 2005 to more than 1.3 million in 2019. The annual rate of population growth reached $5.2 \%$ and this implies that the population would effectively double in only 13.5 years.

Table 1. Population Growth of Abu Dhabi city (1965-2019)*.

\begin{tabular}{lcc}
\hline Year & Population Number 1000 persons & Annual Growth Rate (\%) \\
\hline 2019 & 1323 & 5.2 \\
2015 & 1145 & 5.4 \\
2010 & 879 & 6.1 \\
2005 & 655 & 5.3 \\
2000 & 505 & 5.2 \\
1995 & 392 & 3.5 \\
1990 & 331 & 3.5 \\
1985 & 279 & 4.1 \\
1980 & 229 & 13.8 \\
1975 & 120 & 14.1 \\
1970 & 62 & 14.1 \\
1965 & 32 & 14.8 \\
1960 & 16 & ----
\end{tabular}

*Source: Computed by the researcher according to censuses and Abu Dhabi Statistic Centre (SCAD, 2016), Statistical Yearbook of Abu Dhabi, different years.

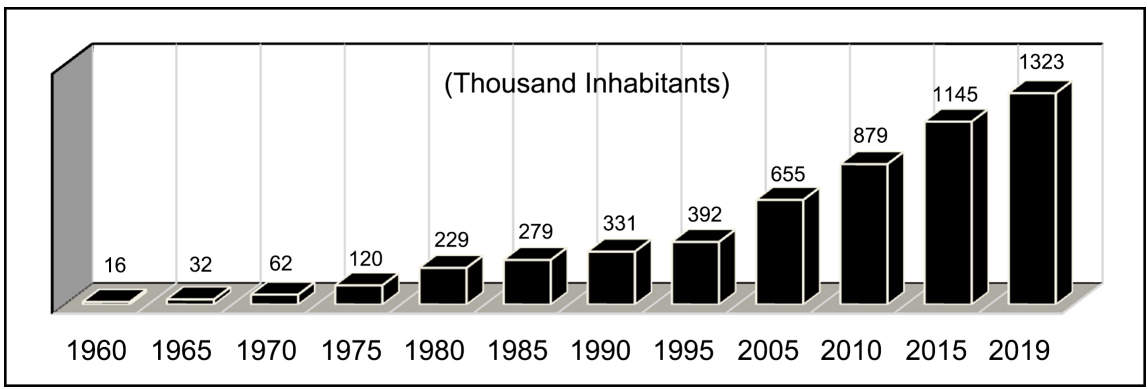

Figure 1. Population growth of Abu Dhabi city. 
As a result of the emirate's population multiplying by a factor of five over the past five 45 years (1975-2020) Abu Dhabi easily ranks as one of the fastest growing cities globally. With a continuous decrease in both birth rate and death rates, it is impossible to consider the population growth in Abu Dhabi as a result of immigration alone. However, that being said, it was predominantly and undeniably driven by the increasing flow of guest workers who constitute approximately $90 \%$ of the population of the emirate over the last decade. According to the statistics in Table 2, the emirate observed a decline in population growth rate from 28.9 to 14.0 per thousand between 1985 and 2019 .

Data in Table 2 indicates that the death rate has declined to about 1.0 per thousand representing the lowest death rate worldwide. This development is due to a number of reasons, mainly:

1) most of the population of the city are adults (19 - 60 years old), the overwhelming majority of expatriates return back to their country of origin at or prior to the age of retirement;

2) the economic and social progress, which led to the improved quality of living and health standards;

3) enhancement in healthcare and education among the population;

At the same time birth rate declined sharply from nearly 32 to 15.3 per thousand during the past 35 years. There is a clear difference in birth rates between the indigenous population and foreigners. The data below shows that birth rate amongst the indigenous population is 34 per thousand compared to only 17.2 for non-citizens. However, the differences in death rates are not the same (Elessawy, 2020).

In brief, the natural increase rate declined from approximately 29 to 14 per thousand from 1985-2019. This means that it has a low impact on the population growth in comparison to the increasing numbers of guest workers which has an important role in the population growth of Abu Dhabi city.

Natural increase leads to a rise of newly born nationals of certain group of age or a decline as a result of the death of certain group of age to such an extent that both cases occur once in the lifetime of an individual. However, the majority of guest workers represent middle-aged men who join the labour force and have an effective role in the development of the city urban expansion, economics and the demographic characteristics.

Economic progress engendered rapid population growth and significant changes in the structure of the labor market of the city. Like the case of most Arabian Gulf urban centers, the city labor market is dominated by expatriate and migrant guest workers. As shown in Table 3 the immensity of the growth in non-national workers over the last four decades is quote clear. Their numbers increased from approximately 87,000 in 1975 up to 331,000 in 1995. And during the following ten years it reached 574,000 in 2005. The inflow of immigrants has continuously increased and it doubled in 10 years to reach more than one million in 2015. The percentage of non-nationals increased continuously from $72 \%$ in 1975 to nearly $90 \%$ of the total population of the city in 2015 . 
Table 2. Birth and death rates and natural increase in Abu Dhabi city in selected years from 1985-2015 (figures per thousand)*.

\begin{tabular}{cccc}
\hline Year & Birth & Death & Natural increase \\
\hline 1985 & 31.8 & 2.9 & 28.9 \\
1990 & 26.6 & 2.0 & 24.6 \\
1995 & 23.0 & 2.0 & 21.0 \\
2000 & 19.9 & 1.6 & 18.3 \\
2005 & 17.2 & 1.5 & 15.7 \\
2015 & 16.8 & 1.2 & 15.6 \\
2019 & 15.3 & 1.3 & 14.0 \\
\hline
\end{tabular}

*Source: Abu Dhabi Statistic Centre (SCAD, 2020), Statistical Yearbook of Abu Dhabi 2020, Population and Vital Statists.

Table 3. The increasing number and percentage of non-national population in Abu Dhabi from $(1975-2015)^{\star}$.

\begin{tabular}{ccc}
\hline Years & Number of Non-National & \% of the Total Population \\
\hline 1975 & 86,760 & 72.3 \\
1980 & 177,246 & 77.4 \\
1985 & 215,946 & 79.3 \\
1995 & 330,848 & 84.4 \\
2005 & 573,780 & 87.6 \\
2015 & $1,024,775$ & 89.5 \\
\hline
\end{tabular}

*Source: Computed from different Abu Dhabi census reports.

The labour market is segmented along different lines with limited labour mobility due to wage rigidities, skill set differences and institutional and cultural factors. In the public sector, United Arab Emirates nationals are more highly paid than the expatriates who have got the same qualifications and who perform the same jobs. This together with the job security, social status and other benefits make the government the most attractive employer to almost all the UAE nationals. The private sector relies on foreign labour that is paid lower wages and work under fixed short-term contracts. Migrant workers account for $99 \%$ of labour in the private sector. The majority of foreigners in Abu Dhabi are male singles although the number of women has also grown during the previous few decades. Most of the women are housekeepers especially from Philippines, Indonesia, Bangladesh and Nepal. Most of the foreign men are hired in the service sectors which require mostly low skills, while foreign women are mainly employed in jobs that are related to domestic services and retail. On the other hand, a large number of highly-skilled migrant guest workers, who are particularly from European and western countries, are also attracted to employment in ur- 
ban centres for the following sectors: Oil and Gas, Finance, Education as well as Investment. The increase in non-nationals, mostly young men led to clear demographic, economic, cultural and social features, to the extent that the effect of foreign immigration with great numbers to the city has left a noticeably unbalanced population composition.

Data from Figure 2 indicates that Emirati nationals represent a minority in their city as a percentage of total population. Arabs and Europeans constitute small portion, but most of the city residents are Asians. Furthermore, Indians comprise approximately $30 \%$ of the total population in Abu Dhabi and they are to be ranked first because they export workers to Abu Dhabi. For instance, Indian, Pakistani and Bangladeshi workers form approximately $50 \%$ of the total population. While the remaining population comprises nationals of other countries including Egypt, Iran, Jordan, Sri Lanka, Nopal, Philippines, Afghans and other Asian nationalities. The number of employees from the UK, USA, and Europe in general has become $3.0 \%$ of the total population of the city. Simultaneously, the percentage of Emiratis is extremely low, approximately $11 \%$ only of the city's total population (Elessawy, 2020).

In 2019, the population density of Abu Dhabi city was 1750 people per square kilometer, and that makes it the second most densely populated city in the United Arab Emirates after Dubai city's density which is 2500 people per square kilometer. The density of population of Abu Dhabi city has decreased from 3400 people in 1985 to 2160 in 2005, and to 1750 people per square kilometer in 2019. This decline in the density was accompanied by a great urban expansion of the city out of the main island toward the new neighborhoods in the mainland. Mainly southward toward Khalifa City, Mohamed Bin Zayed, Musaffah and Al Shahama cities, and eastward toward the new reclaimed surrounding islands of Abu Dhabi islands as Yas, Al Reem and Al Saadiyat islands.

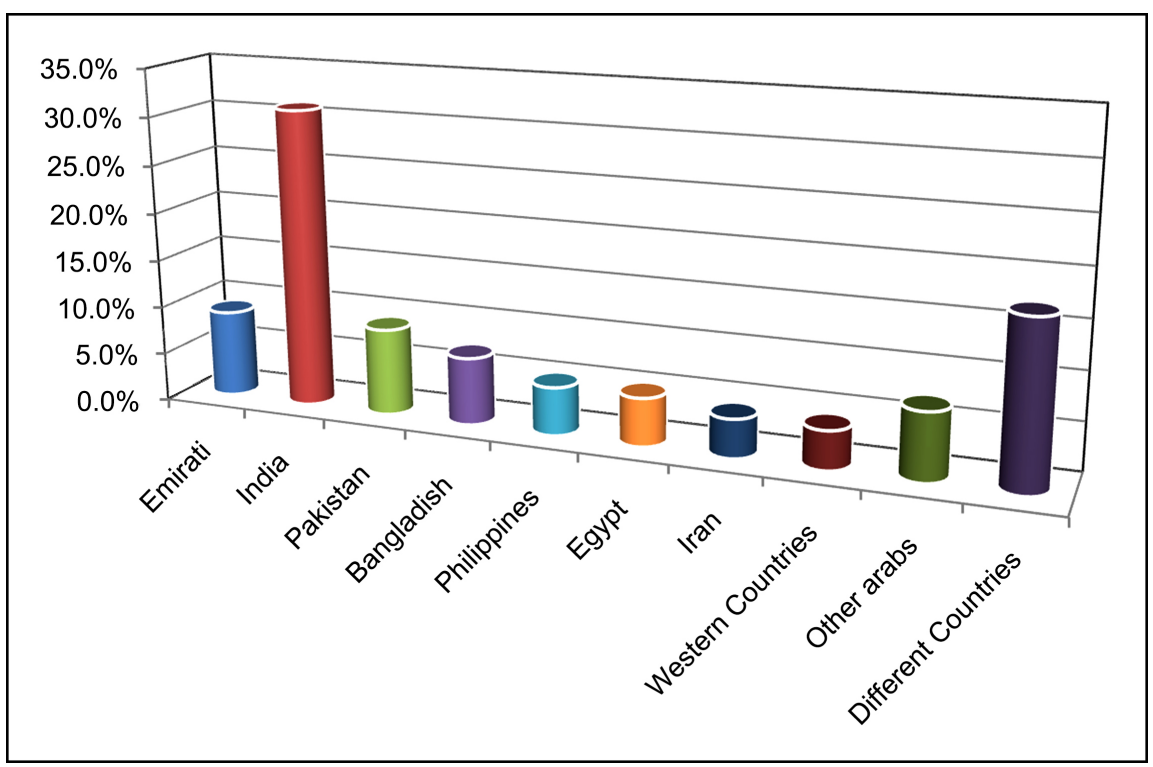

Figure 2. Percentage of nationalities of population of Abu Dhabi city. 
The density of Abu Dhabi city's population varies from one place to another. Abu Dhabi city has the highest density of population (more than 30 thousand people per square kilometer) in the central residential downtown areas including Al Khalidiya, Al Markaziah, Al Karamah Al Zahia and Al Wehdah areas which are located in the northern part of Abu Dhabi Island. Another zone of high population density (between 7 to 30,000 people per square kilometer) is in the suburban districts of Al Mushrif, Al Nahyan, AL Musalla, Al Rayhan and Al Khubairah. In the densely populated areas, most of the concentration is achieved with medium and high-rise buildings. By contrast, low-density areas (less than 7000 people per square kilometer) are concentrated in the southern suburban areas in the southern part of Abu Dhabi Island including Al Moroor, Al Muntazah, Al Madinah Al Riyadiya, Al Bateen and in the Embassies District. Away from Abu Dhabi Island, low-density residential areas are concentrated in the new extensions of the city in the suburban areas on the mainland such as: Khalifa, Masdar, Al Falah, Mohamed Bin Zayed, Musaffah and Al Shahama cities. These are partly dominated by the attribution of the square housing plots, planned and dedicated to the Emirati people to build their private villa compounds or low height buildings.

Thus, when one finds a population of a city having increased from 32,000 to 1.323 million in only 55 years (4000\%), such as in the case of Abu Dhabi, one can comfortably label this an abnormality.

\section{The Abnormal and Rapid Urban Sprawl of Abu Dhabi City}

It is worth noting that the rapid population growth of Abu Dhabi city especially after 1973 when the city became a capital of the UAE and the oil boom continued to draw a large number of people to Abu Dhabi, necessitating further development. That dramatic population growth accompanied with abnormal urban growth to meet the continuous demand of housing for the foreign expatriates which they constituted more than $85 \%$ of population.

The city of Abu Dhabi is located on an island in the Arabian Gulf off the Central West Coast. Most of Abu Dhabi city is located on the island off Abu Dhabi itself, but it has many new residential neighborhoods on the mainland such as Khalifa City (A, B, and C), Al Maqta city, Al Raha Beach, Al Bahia City (A, B, and C), Al Shahama; Al Rahba, Masdar City, Baniyas, Shamkha; AL Wathba, Mohamed Bin Zayed city, Shakhbout City, Bani Yas city and Musaffah city. In addition to adding new land by reclaiming and raising land level of the surrounding islands as: $\mathrm{Al}$ Reem, Al Jubail and Saadiyat Islands in the northeast. Yas, Samaliyah and Sas Al Nakheel islands in the southeast. Mangrove National Park to the east. Marina and Lulu to the north of Abu Dhabi Island. AL Ras Al Akhdar in the northwest and Hudayrat island to the west of Abu Dhabi Island (Figure 3).

Abu Dhabi has undergone a profound transformation from a barren semi-island and poor settlement in the 1960s to a metropolis crowned with high-rise build- 
ings and marble-fronted architecture in the new millennium. The rapid expansion of Abu Dhabi transformed the city from a small village into a global city. The total built-up area of the city increased from only half a square kilometre in 1955 to 758 square kilometres in 2018 (see Figure 4). This abnormal urban growth is apparent in the city's size, territory and urban morphology. The discovery of oil has proven to be one of the principal drivers of Abu Dhabi's development. In a scrutinized study of urban growth maps of Abu Dhabi reveals that the city can be divided into four different stages of urban development. These stages can be described as follows:

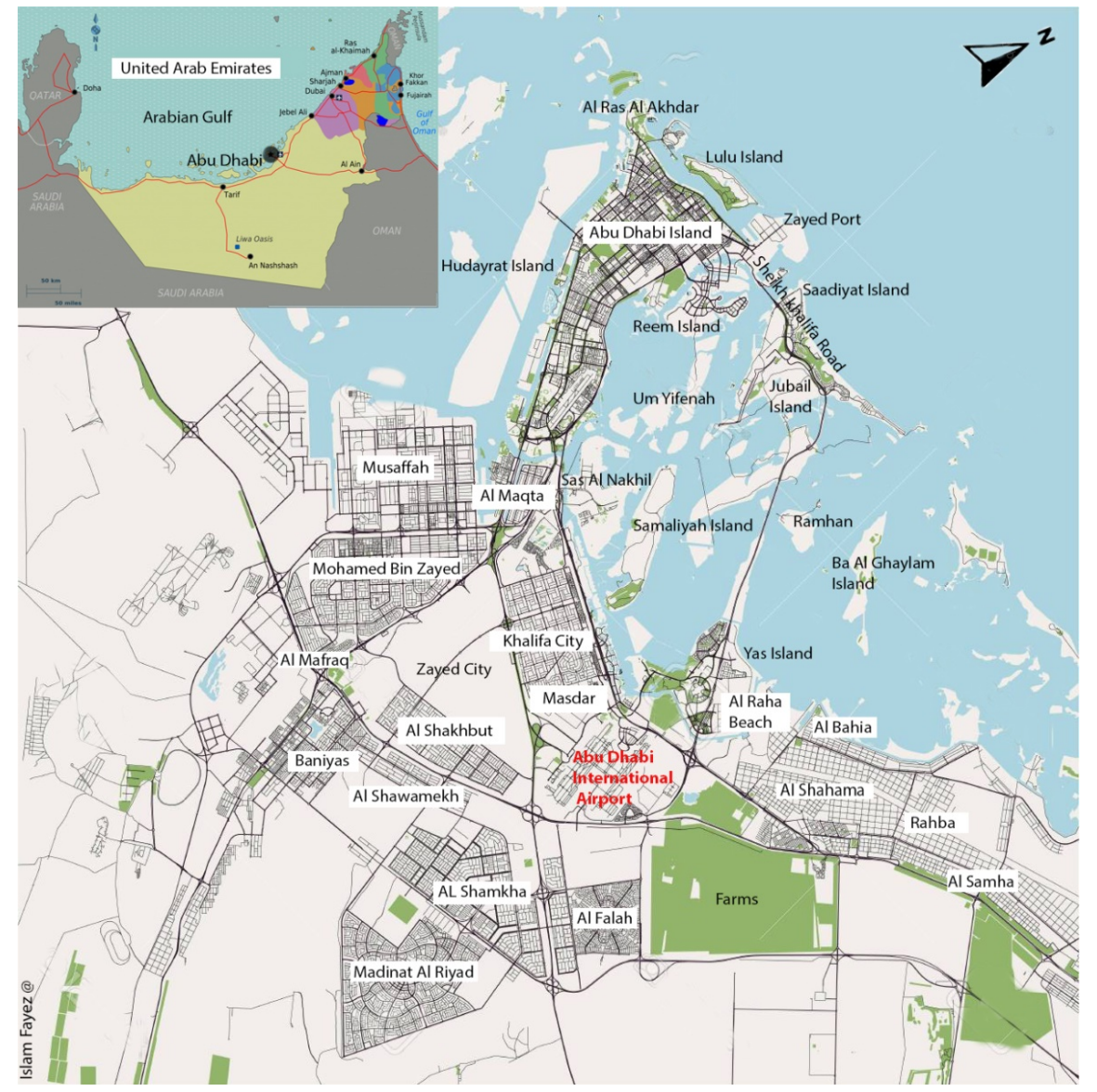

Figure 3. Boundaries of the urban expansion of Abu Dhabi city in 2019.

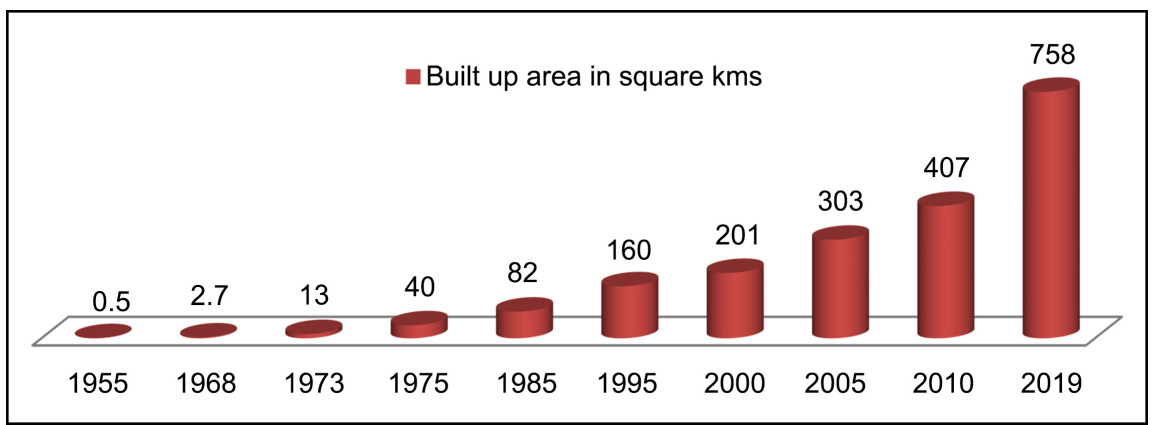

Figure 4. Urban growth of Abu Dhabi city from 1955-2018. 
- Stage I: Urban origins of Abu Dhabi before 1973;

- Stage II: Planned suburban growth from 1973 to 1989 (ambitious city vision);

- Stage III: Constructing a modern capital city from 1990-2005;

- Stage IV: A city for the $21^{\text {st }}$ century (from 2005 to present).

Every stage has its own specific urban characteristics as shown in the following study.

\section{Stage I: Urban Origins of Abu Dhabi before 1970}

We can divide the urban history of Abu Dhabi during this period into two different phases, the first one describes the poor situation before 1967 followed by the second phase, which showed the first actual uprising beginning of a new urban center from 1967 to 1972. Until the end of the sixties of the twentieth century Abu Dhabi settlement was a very poor and isolated fishing village with slow growing economy and population. The inhabitants lived in houses made of palm fronds called (Arish), due to the lack of resources and particularly capital, so the expansion of its area was limited. In 1955, the total built up area estimated by only one-half square kilometer inhabited by a small population (less than 15 thousand) concentrated on the northern coast of the island.

Although oil was discovered in 1958, only a few developmental steps were taken towards improving living conditions (Elsheshtawy, 2008). The ruler Sheikh Shakhbout wanted to maintain the tribal and Bedouin society. The primary structure that dominated the capital's landscape was the ruler's large rectangular fort and residence with towers at the corners. There were several houses spread along the seashore and between Qasr Al Hosn fort and the beach. The majority of these were made from palm fronds (Arish), while others belonging to the more affluent merchants were built using coral and stone. At the back of the town there were "some indifferent wells" and the shallow pits yielded water at a place of three to four miles away from the town (Maitra \& Al-Hajji, 2001).

As a further hindrance to development in 1961, the ruler imposed a ban on any new construction whereby any contractor/developer had to get prior construction permits, which was not always forthcoming. The ruler also disliked non-Abu Dhabi Arab merchants (Davidson, 2007). As a result, the town remained in a persistent state of underdevelopment with many residents leaving for nearby Dubai which was flourishing. A few steps were taken towards improving living conditions such as the construction of a new school which was opened in 1958 (Elsheshtawy, 2008).

From 1961 to1966, the city's development remained modest, even after it began exporting oil in 1962, due to its conservative governance system. Shakhbout was also reluctant to spend large sums of money on development. Even the contributions and involvement of foreign consultancies and expertise were received with unwillingness and implementation pressures. Until 1965, Arish construction dominated Abu Dhabi's landscape; there were no signs of modernity, no communication services, no electricity and no fresh water supply services (Bani 
Hashim, 2016). The settlement site of Abu Dhabi itself was not more than a village built on sand, where roads were very primitive and there was only a solitary humble hotel used primarily by oil company representatives.

Stage I - Phase II: The year 1966 was a significant time for the city; when Sheikh Zayed Bin Sultan Al Nahyan became ruler of Abu Dhabi. Zayed is known as the founding father of the UAE and "the man behind Abu Dhabi's master plan" (Ghazal, 2013). His vision entailed a social mission aimed at urbanizing the city and enhancing the living conditions through housing and agriculture. In an effort to create a city, Sheikh Zayed encouraged Bedouins to leave the desert and settle on the island by guaranteeing a free house to every person of Abu Dhabi origin. In 1968, under the direction of Sheikh Zayed and the Council of Ministries (the Executive Council) "The Preliminary Direction Plan” was created to accommodate the increase in population by building permanent settlements for nomadic tribes (Elsheshtawy, 2016). This marked the birth of national neighborhoods in Abu Dhabi.

As a result, Sheikh Zayed issued decrees pertaining to the formation of governmental departments relating to the health, education, paved roads, planning and the public works sectors. In addition he commissioned a projects to link Abu Dhabi island with the main land by establishing Al Maqtaa bridge in 1967. Separately he commissioned the Al Bateen Airport in 1969 thus connecting Abu Dhabi Island with the middle east and north Africa.

Sheikh Zayed made his vision for developing the city clear: he wanted to create an environment to facilitate the economic, cultural, and spiritual growth of his people. This included the preservation of their cultural traditions in planning and design, such as the inclusion of an Arab-Islamic identity in architecture, the preservation of mosques and historic sites, and the encouragement of social and tribal cohesion through neighborhood design. Eventually, to this he added his desire to create a modern city. Zayed welcomed foreign expertise in the development of Abu Dhabi. The man behind the master plan who shaped the vision for the city is Dr. Abdul Rahman Makhlouf (Director of A. D Town Planning from 1968-1976) who became the father of Abu Dhabi's modern urban development. The Egyptian Planner Abdul Rahman Makhlouf, was hired by Sheikh Zayed in 1968 to solve the city's housing gap and build 2000 family units called Sha'biyat house (popular housing). That Sha'biyat were meant to house Bedouin families who had been living a nomadic lifestyle equipped with mosques, services, and schools, these clusters formed neighborhood units. The houses were arranged in a staggered formation so that each family could have enough land around the house to build future additions. The Sha'biyat have clean lines, simple looks, and use simple technologies. It is located near the downtown area of Abu Dhabi and is surrounded by a compound wall and a few more Sha'biyat houses which have courtyards used for small livestock and gardening. Some of these houses were rented out to expatriate workers. These houses reflect Makhlouf's Sha'biyat design, with minimal corridor space and 
ample outdoor living areas. Poor maintenance has led to severe deterioration of these particular Sha'biyat, but they are still functioning homes. Accordingly, the main roads of the old Abu Dhabi settlement site were designed in straight lines. Separately, a series of essential public projects were constructed. Old houses were slowly torn down and replaced with simple, functional buildings that lacked any kind of ornamentation (Elsheshtawy, 2008).

The second half of 1969 saw a dramatic decline in the urban development; several projected works were cancelled while some already showing above the ground were abandoned. The incentive for this action was a sudden awareness that free spending had stopped the flow of cash. Government debts were not being paid on time, while the first few years of the 1970s were quiet in terms of the city urban development. By 1970, Abu Dhabi's urbanized area had grown to 3.5 square kilometers, and its population increased to reach nearly 62,000 inhabitants.

By 1971, Sheikh Zayed embarked on a massive housing program with the goal of providing residential accommodation to Abu Dhabi citizens, and the regional nomadic tribes in particular. The old Arish settlement site was slowly diminished and replaced with simple, functional buildings that lacked any kind of ornamentation. The local inhabitants who were forced to abandon their old palm-frond dwellings were compensated handsomely by the government. However, with that money they could build new homes and establish small businesses. Sheikh Zayed's strategy for putting seed capital directly in the hands of his people and jumpstarting the local economy. In addition to monetary compensation the Ruler gave each Abu Dhabi citizen three, and in some cases four, pieces of land to develop as residential, commercial, industrial and agricultural enterprises. Because of this, construction marked the largest economic activity by 1969 , and many of the leading merchant families began to import construction goods. Subsequently, the first generation of nontraditional houses and buildings were built from reinforced concrete (Bani Hashim, 2015). The year 1972 saw the inauguration of Zayed Port, Abu Dhabi had its first local port and since then the city's trade and economy have forever changed. The city also saw an expansion of its modern hotels, the opening of the Hilton Abu Dhabi in 1973 represented a new era of internationalism, followed by Le Meridian and Sheraton's appearances some years later were the second wave of development.

\section{Stage II: Planned Suburban Growth from 1973 to 1989 Ambitious City} Vision

It is worth noting that, in the early 1970s to the late 1980s there was a surge in construction activity and the emergence of Abu Dhabi from a small fishing village to an internationally recognizable urban settlement, something which is symptomatic of an "instant" city whose existence is derived from its relatively sudden oil wealth. This is also associated with the emergence of the United Arab Emirates as a political entity in 1971 after seven the emirates decided on a confederation. Furthermore, a decision was made to choose Abu Dhabi as the capi- 
tal city of the unified nation state. After the initial modernizing frenzy of the late 1960 's, subsequent waves of development seemed to wash over Abu Dhabi from the gulf layering higher buildings on the northern part of the island and pushing the city further south until it sprawled into the mainland (Dempsey, 2014). Some of the main elements of the city, recognizable today, originated at that time.

In October 1973, the Arab-Israeli war led to an oil embargo that caused oil prices to spike. While the "oil shock" reverberated through much of the western world, triggering shortages and slowing economies, the additional revenues accelerated urban development in Abu Dhabi in the following years. During the period of 1971 to 1985 , a planned suburban growth occurred and a new master plan for the city was conceived. Accordingly, main roads in the northern part of the island were designed in straight lines, also a series of public works projects were constructed such as governmental buildings, desalination plants and power generation facilities. Major transportation developments were planned to connect the city districts on both sides of the creek. 1974-1979 saw many large-scale development projects and the horizontal spread of the island to the north, west and the south. This period is characterized as giving Abu Dhabi its first push toward modernization and change its landscape to be an accurate urban center by removing all buildings in the "old village" (North of Qasr Al Hosn) and replace them by modern houses in Sha'biyat, Apartment buildings were rapidly constructed to satisfy the high demand generated by an expatriate population that was attracted to working and living in Abu Dhabi. In 1973 and 1974, the construction of new buildings was aimed at providing offices for the large number of companies, including oil and oil services companies, shipping agents, importers, consultants and banks, and later more office space was needed for the expanding local administration and schools. Other private sector demand, government departments, and the fledgling (but rapidly growing) military establishment were all key drivers of the population growth and thus demand drivers for housing solutions. These factors contributed to a housing problem as supply was extremely limited (Bani Hashim, 2016).

Street names appeared for the first time in 1974 in the inhabited area of the northern parts of Abu Dhabi Island. The inner-city roads and main roads are quite organized. Starting from the Corniche, all horizontal streets are oddly numbered, while all vertical streets are evenly numbered. Thus, the Corniche is Street No. 1, Khalifa Street is Street No. 3, Hamdan Street is Street No. 5, Electra Street is Street No. 7 and so on. Conversely, Al Salam Street takes No. 8. The names were based on three main concepts outlined by the Ruler: Streets were to be named after members of the Al-Nahyan family who had an important role in the development of Abu Dhabi (e.g. Hamdan Street or Khalifa Street); some streets were to be named after geographically significant locations linked to the story of Abu Dhabi (e.g. Delma Street); and finally, other streets were to be named in ways that made people feel happy (e.g. AL Salam (meaning peace) Street and Al Saada (meaning happiness) Street (Ghazal, 2013). From 1974 to 
1979, the main road network was extended to include the East Road or Al Salam Street, Western Corniche, Arabian Gulf Street and the Mussaffah road and bridge (1978). A significant landmark, known as the Mercedes Roundabout, was also developed towards the southern end of the island near the Zayed Sports City area. The Al-Bateen Airport was expanded slightly in 1975, while work on a new international airport on the mainland was started in 1977. Development projects for electricity, water, telecommunications, and sewerage (first phase in 1976-1982) networks were also planned (Bani Hashim, 2016).

During the period 1974-1979 many large-scale development projects appeared and the horizontal spread of the island to the north, west and south increased. This period is characterized as giving Abu Dhabi its first push toward modernization and changing its landscape to be a true urban center. Apartment buildings were rapidly constructed to satisfy the high demand generated by an expatriate population while work began on new residential areas for Emirati nationals featuring low-cost houses and villas. Community services such as mosques, clinics, schools, and markets were also provided in residential neighborhoods. Development even took place on the mainland, with the establishment of settlements such as Al Wathba, Bani Yas and Mafraq. Furthermore, the greening of Abu Dhabi was stepped up, with several public gardens and parks as well as trees allocated throughout the city (ADM, 1996). Another significant development during that time was the formation of an area in the northwestern part of the island called Khalidiyah. Here, around 70 buildings were constructed along with 800 homes and villas. Separate areas on the island were established for contracting companies' camps, employees' housing, and 184 senior officials' villas. Work continued on the Corniche waterfront and began on the Capital Garden, (Bani Hashim, 2016).

Commercial and mixed-use building heights ranged between three and ten floors. Between 1975 and 1979, 628 buildings were constructed in Abu Dhabi, a significant increase from the 90 buildings constructed in the period 1970-1974 (ADM, 1996). During that period, 1292 single-story buildings, 347 two-story buildings, 647 villas, and 5,326 national or low-cost houses were also built, compared to 654 single-story buildings, 73 two-story buildings, 162 villas, and 1,664 national houses, respectively, between 1970 and 1974 (ADM, 1996). Construction in the city was also affected by the Khalifa Committee which was established in1976 to assist persons of Abu Dhabi origin with the financing and building of housing and commercial projects. The total built up area of the city increased to 40 square kilometers in 1975, a year which saw the first population census being carried out in the United Arab Emirates. The census recorded the official number of residents in Abu Dhabi city at 120,000. However, constructing such a large number of buildings within a short time span also led to fears of overdevelopment. Thus, a slowdown began in 1977 when many high-rise buildings were completed, causing an excess supply in the housing sector, which had around 15,000 empty apartments. "To Let" signs were visible all over the city 
(Elsheshtawy, 2008).

Programs were set up to establish many hotels (e.g. Sheraton Hotel and Resorts, completed in 1979; Al Ain Palace Hotel; Khalidiya Palace Hotel), public buildings, hospitals (e.g. Al Jazeera Hospital, Beach or Corniche Hospital), and departments and ministries (e.g. Ministry of Finance, erected in 1979). Movie theatres (e.g. El Dorado Cinema), bookshops (e.g. All Prints), shopping centers (e.g. Hamdan Center), and embassies (e.g. Swiss, Egyptian, Sudanese, and Iranian) opened. Sheikh Zayed commissioned architects to build large sports or cultural complexes and government buildings such as the National Theater and the Courthouse (1977), the Zayed Sports Complex (1978), and the Cultural Foundation (1979).

In addition, new land was added to Abu Dhabi island northward via substantial dredging and land reclamation operations which saw low level land of the gulf (an area to the west of the Corniche) being reclaimed. This is called Ras $\mathrm{Al}$ Akhdar (now famous as the area in which the luxury Emirates Palace is located which opened in November 2005), and a breakwater structure was also built to protect the Corniche being reclaimed as well as to create additional space on the island. In the northeastern parts of the island, close to the port of Zayed, work began on the Tourist Club area where new residential areas for Emirati nationals were set up with low-cost houses and villas. Community services such as mosques, clinics, schools, and markets were also provided in such residential neighborhoods. The development of settlements on the mainland was accelerated by further development in Bani Yas, Sweihan and Shahama, which was encouraged not only through low-cost housing schemes but also through a number of major projects that had a marked effect in spreading development on the mainland. The most notable of these projects are the International Airport (completed in 1981). From 1980 to 1988, 798 towers, 5336 villas, 7907 national or low-cost houses, 2885 single-story buildings, and 912 two-story buildings were built, the majority constructed between 1980 and 1984 (ADM, 1996). Statistics for the year 1985 show that the island was around 96 percent urbanized (ADM, 2003). By 1988 there was considerable liquidity in the market, and with urban planning being carried out haphazardly, or on a piecemeal basis, the Executive Council decided that a comprehensive plan for the city was needed to manage growth (Bani Hashim, 2016).

The built-up area of the city was soon to be relieved of pressures as a result of the construction of Khalifah City, the first major multi-purpose area outside of Abu Dhabi island. Khalifah City was aimed at providing a greater supply of land for residential and commercial projects to further accommodate Abu Dhabi citizens looking to build their own homes and commercial premises. Khalifah City was soon accompanied by the new international airport and a new industrial area on the mainland called Mussaffah. Following on from these large-scale projects a new bridge (Mussafah) was built in 1978. This bridge became an important access road to connect Abu Dhabi Island with the new urban extensions, 
as highlighted above.

During the 1980's Abu Dhabi witnessed another wave of massive urbanization due to the increase in oil prices (Hume, 2008). In 1988, 'The Master Directive Plan for Abu Dhabi and its Environs' ("MDP”) was divided into four five-year phases from 1990 to 2010. The plan was introduced to manage uncontrolled development, enhance the efficiency of the urban land-use system, formalize community planning and facilitate sufficient residential zoning for both citizens and non-citizens to satisfy the housing needs of different population segments. The MDP resulted in massive suburbanization in the mainland that challenged the city's physical and environmental sustainability (Alawadi \& Benkraouda, 2017).

The 1980's are characterized as the city's "second facelift" (Hume, J., 2008), with several factors markedly affecting the urban structure of the city during this period: First, the mediocre quality of the first generation of buildings, as well as a heavy turnover of tenants and a housing filtering process, resulted in demolition and reconstruction efforts (urban renewal) throughout the city. Second, the formalization of building regulations allowing building heights up to 17 or 20 stories resulted in a substantial period of vertical expansion. Separately, renewal inside "superblocks" saw a change in the building form from first-generation low-cost one and two-story housing into medium-rise (up to seven stories) apartment buildings. Moreover, in the central area high-rise buildings proliferated in place of medium rise buildings. Consequently, densities increased in these areas.

Finally, in 1981, the government via the Khalifa Committee expanded into the Department of Social Services and Commercial Buildings (DSCCB) and pressed on with facilitating the process of building projects on behalf of Emirati nationals, from the design brief to construction and from maintenance to rent collection. As a result of increasing high buildings, Emirati nationals were relocated to the periphery, or to the "pristine" parts of the city away from the densely populated areas. The older buildings were sublet to expatriates and then to less affluent households. Some of the vacated low-cost or traditional houses were also internally subdivided by citizens and rented to low-income expatriates. After many years, with little or no maintenance, the buildings became dilapidated and earmarked for demolition. The fresh investment flows from wealthy Emirati nationals provided more reason to knock the buildings down and utilize scarce land for a denser occupation with higher buildings (Othman, 2006).

Economic, social and physical transformation of the city and the major developments in urban structure continued via rapid urban expansion during the 1980s. The urban area expanded enormously as the government invested into improving the road system, building tunnels, bridges, container terminals, trade harbors as well as industrial and residential areas. During the same period financial, business and administrative centers were established in different parts of the city. This attracted a large number of foreigners to seek employment with com- 
panies growing or newly expanding their presence into Abu Dhabi. On top of that, the total population increased from 229,000 in 1980 to 331,000 inhabitants in 1990. As a result, the total built up area of the city reached 160 square kilometers in 1995.

\section{Stage III: Constructing a Modern Capital city from 1990-2005}

In the early 1990s, Abu Dhabi took a strategic decision to emerge as a major international-quality metropolitan area. The MDP was prepared to guide the economic and physical development of the city into the $21^{\text {st }}$ century. Anticipating rapid urban growth, and given the limited area on the island, the plan recommended several "extensions" to the city. These included the development of the islands surrounding the city particularity Saadiyat and Hudariyat. Further growth towards the mainland was suggested along two axes: highways leading to Dubai and Al Ain. The MDP also recommended the conversion of Mussafah from an industrial area to a residential area. Furthermore, the direction of growth would be limited to the Dubai and AI-Ain axes (ADM, 2003).

During the 90 's of the $20^{\text {th }}$ century significant developments were approved or directly sponsored by the government including the bus terminal station, the municipality building, the equestrian club, more hotels, restaurants, Abu Dhabi mall, retail shops, and additional office buildings/complexes. The sewerage network was in its third phase, and greening the city had reached its prime: When once there was once only one big tree, by 1995, there were about 130 million trees in the emirate (Salloum, 1997) and 33 public parks in Abu Dhabi were established (ADM, 1996).

A detailed evaluation occurred in the process of urbanization of island, which led to the expansion of the urban land area via conversion of old buildings into a system of advanced constructions, either in the middle of the city (for apartment buildings) or for villas. The expansion of the public sector led to the spread of government institutions and offices all over the island, while new residential areas outside of the Central Area are often interrupted by institutional areas and palaces that occupy large tracts of land. During this period, Abu Dhabi's urban landscape was shaped by another change in building height regulations as well as some urban land use changes. The changes permitted taller buildings, with heights up to 30 floors in the Central Area, while high-rises of up to 20 floors were permitted in the Tourist Club area. In some residential sectors, low-cost houses were demolished and replaced with villas or three-to-six story investment properties (Makhlouf, 2006). Demolitions took place for more than 200 old low-cost houses and old tower buildings. The southern part of the island up to and including the area Bein al Jisrein (Al Maqta) was further developed, and an Embassies District was formed. Development intensified on the mainland, with residential areas in Khalifa City, Mohamed bin Zayed City, Mussaffah, and Al Shamkha coming to life and highways built to access them (Bani Hashim, 2016).

The city continued to expand horizontally, and implementation of traffic light 
systems replaced most of the roundabouts in the city and carriageways were expanded from two to three lanes. The city also grew vertically, as buildings were demolished and reconstructed at greater heights. The development was expanded onto the mainland, several bridges and tunnels were built, and building heights in the central business district ("CBD") were further increased while lower densities were achieved towards the south of the island and on the mainland. Aluminum cladding and reflective glass were the materials of choice during this period. Mangrove planting and green area development were also heightened.

The urban growth of the city was not limited to the horizontal expansion on Abu Dhabi Island, nor the new neighborhoods on the mainland, but rather the nearby islands. The waterfront of Abu Dhabi was, and is still, utilized extensively to the benefit of the city and the emirate and was substantially extended by adding new land (by raising land levels of the adjacent islands to that of the city). Dredging and reclamation also continued at a steady rate, increasing the landmass of the island to 96 square kilometers by 2001 (ADM, 2003). The newly created landmass included the islands of Saadiyat, Yas, Reem, Maryah, Hudariyat and then the mainland shores of the Corniche and Khaleej Al Arabi street. But Raha Beach and Musaffah are the most characteristic examples of this model of development. The famous Lulu Island, which was reclaimed in the early half of the 90s to serve as a breakwater for the city itself, remains undeveloped; however, its future also holds the possibility of urban development. On the other hand, urban takeover of adjacent islands (i.e. Saadiyat and Yas) has led to the engulfment of significant mangrove marine forests and various smaller islands by a city ring, thus, having to consider them as parts of the urban agglomeration and therefore adding them to the calculations. The Corniche was extended into the sea in the late 1990s, and in the summer of 2004, the new Abu Dhabi Corniche Road, 8 kilometers in length, was inaugurated. The road network included the creation of parking facilities, parks, and widening of the road from three lanes to four lanes in each direction. The land created between the existing Corniche gardens and the new road was developed into a major recreational and leisure area including children's play areas, separate cycle and pedestrian pathways, restaurants, cafés and the Corniche Beach. Across from the Corniche, the Marina breakwater near Ras Al Akhdar was reclaimed and expanded and became the location of one of the city's first malls, Marina Mall which was opened on 28 March 2001.

Abu Dhabi city, like most of the Arabian Gulf cities, is one of the most prominent examples to note of a hybrid city process, whereby its architectural styles are subject to substantial influence from various global urban ideas, political vision, and technologies (Lieto, 2019). The total built up area of Abu Dhabi city increased from 82 square $\mathrm{kms}$ in 1985 to 303 square kilometers in 2005 as shown in Figure 4.

\section{Stage IV: A City for the $21^{\text {st }}$ Century (2005 to present)}

The year 2004 witnessed the death of Sheikh Zayed and the transfer of power to his son Sheikh Khalifa, and so some changes were introduced to push invest- 
ment in urban form. Chief among these was a change in the property ownership law, allowing the sale of government granted land by nationals, as well as introducing a form of ownership by foreigners. The generous welfare state was thus being corporatized and privatized. These developments were expected by many industry insiders and this led to an approximate $25 \%$ per annum increase in construction activities over the following three years (Elsheshtawy, 2008).

Increasing investment and demand for housing led to a huge building boom in Abu Dhabi, with development expanding onto the surrounding islands and the mainland. Building height permissions along the northern part of the island and in the CBD were further increased, partly in the name of creating "iconic" towers. In addition, the road network was further expanded and some important landmarks were demolished while new ones were constructed such as the Emirates Palace Hotel and Sheikh Zayed Grand Mosque. Furthermore, by 2013 several areas around the city were redeveloped, including $\mathrm{Al}$ Bateen, Ras Al Akhdar, and the Corniche.

Since 2005 to present, the city witnessed a population growth boom, where its population increased from 655,000 in 2005 to 1,323,000 inhabitants in 2019 (Table 1). At the same time another boom in urban expansion happened as a result of development expanding onto the surrounding islands which include the islands of Saadiyat, Al Reem, Yas, Samaliyah, Sas Al Nakhail (East of Abu Dhabi Island). More urban sprawl was observed in eastern and southern neighborhoods such as Masdar City, Al-Shahama, Mohamed Bin Zayed city, Bahia city, Al-Raha Beach, Al-Maqta City, Al-Shamkha City, Al-Falah City and Madinat Al-Riyad City on the mainland (Figure 3). The road network was further expanded, including the construction of many new bridges and tunnels such as the Sheikh Khalifa Bridge (2009), to link the northeastern part of Abu Dhabi island with Saadiyat island, Sheikh Zayed Tunnel and Bridge in 2010 to link the city with the eastern Dubai road and mainland to the southeast of Abu Dhabi Island. Within the eastern side of Abu Dhabi Island many bridges were constructed such as Al-Saada bridge to link the main island with Al-Reem island in 2011, in addition to eight short bridges to link Abu Dhabi and Al-Reem island with Al-Mariyah island. In 2018 Um Yifenah bridge has been constructed to link both Al Reem and Um Yifenah islands. On the western side of Abu Dhabi island there is Al Bateen Bridge to link the city with Hudayrat island (opened in 2012).

The building heights along the northern part of Abu Dhabi Island, and in the $\mathrm{CBD}$ were further increased. Some important landmarks were demolished, while new ones were built, such as the Emirates Palace Hotel and Sheikh Zayed Grand Mosque. Furthermore, several areas around the city were redeveloped, including Al-Bateen, Al-Ras Al-Akhdar, and the Corniche By 2013, the city had been elevated to an area of architectural design eminence with a stunning skyline boasting some of the tallest skyscrapers in the world and innovative buildings pushing the limits of architectural imagination like never before. 
Abu Dhabi already has 38 "super skyscrapers" (150 meters height and above) throughout the city. Some of the tallest buildings on the skyline include the 381-meter-tall Mohamed Bin Rashid Tower (2014), the Adnoc Tower (342 meters, 2015), the Landmark Tower (324 meters, 2013), El Etihad Tower T2 (305 meters, 2011), Sky Tower (292 meters, 2010), and City of Light Tower (282 meters, 2015). Most of the 38 skyscrapers (approximately 70\%) were built during between 2011 and 2013. The wave skyscrapers construction declined sharply thereafter - only two skyscrapers were built during last two years (Al-Jawhara Tower in 2018 at 134 meters and Fairmount Tower in 2019 at 162 meters). These skyscrapers have transformed the city's skyline and ranked Abu Dhabi city in the top 35 cities in the world with the highest number of buildings over 150 meters in height (Skyscraper Center.Com). It is worth noting that "skyscrapers" and tourism are related because skyscrapers have the ability to build-up the image of a particular location in the highly competitive global capitalist milieu within which tourism operates. In the tourism sector, skyscrapers provide space to operate hotels, shopping centers, restaurants, and so forth. Skyscrapers have become a tourist attraction in themselves, and tourism growth has spurred the construction of more skyscrapers for multiple purposes. Thus, contemporary architecture has transformed Abu Dhabi city into a world-class tourist destination (Mtapuri \& Giampiccoli, 2017). There are many hotels that have been built to meet the increasing numbers of tourist and business. According to 2019 data there were 169 hotels in Abu Dhabi (54 5-star and 364 -star) that received approximately 5.13 million guests (Abu Dhabi Hotel Performance report, 2019).

Although the global economic crisis of 2008 saw a decline in the construction industry throughout the UAE, Abu Dhabi enabled itself to remain stable by pursuing the world's first carbon-free city, Masdar City. Al-Reem Island, Al-Maryah Island, Yas Island and Al-Saadiyat Island are the locations of some of the major urban development shaping the city. Currently, Al-Reem Island could be considered "the next downtown" core of the city where additional high-rise towers, schools and hospitals are being built to serve the residents and visitors of Abu Dhabi (Allawi, 2017). Branches of many renowned universities, 23 in total, such as Sorbonne, New York, Strathclyde Business School and others have been established to provide high education for Emirati nationals, foreign students as well as children of foreign expat workers. In addition, several golf course facilities and the Al-Forsan (Equestrian) International Sports Resort (located in Khalifa City) have added a new dimension to Abu Dhabi city also.

As the country continues to diversify its economy, various aspects of potential economic sectors have been initiated by the government including the creation of smart cities/communities, and healthier living through investments in the healthcare sector as well as the current move towards a sustainable future for the emirate via promotion of eco-urbanism such as in the case of Masdar City, a prime example of Abu Dhabi's attempts to design and engineer an eco-city of 
the future (Federico, 2015).

Abu Dhabi's economic diversification strategy incorporates a combination of business, luxury, cultural, and leisure tourism; the construction of specific new world class museums such as the Louvre Abu Dhabi on Saadiyat Island in 2017, and venues for global business conventions and gatherings (Abu Dhabi National Exhibition Center) have undoubtedly propelled Abu Dhabi onto the world stage. This is further cemented in the arena of international sports due to Abu Dhabi now hosting a Formula 1 race every year since 2009 at the Yas Marina Circuit on Yas Island as well as the Red Bull Air Race World Series. It is clear that the various aspects of real-estate development, including hotels, malls, waterfront, nature reserves, beaches and other tourism facilities, can be seen as all working together towards the same aim of making Abu Dhabi city an international business and tourism hub. It is therefore not surprising to find Abu Dhabi with a high ranking among various world city league tables. In 2020, Abu Dhabi was ranked the safest city in the world for the fourth year running by the statistical analysis of website Numbeo (Numbeo.com), and also ranks highly on multiple established "quality of life" league tables.

Today Abu Dhabi city is one of the international hubs of services, commerce, and leisure. Central to this planned urban growth is the construction of a series of mega projects that are sometimes described as cities within Abu Dhabi city. Principal among these projects are: Khalifa City, Zayed City, Mohamed Bin Zayed City and Shakhbout City south-ward along Al Ain Road. Along the northeast direction there are many modern communities as Al Reem island, Al Bahia, Alshahamah, and Al Rahba which is located along Abu Dhabi-Dubai road (Figure 3). Nowadays Abu Dhabi city comprises many residential communities offering leisure, entertainment, and giant shopping malls. The total built up area of Abu Dhabi city increased to reach 758 square kilometers in 2019. There is a continuous urban sprawl especially in the new islands of Al-Reem, Yas and Al-Saadiyat islands to the east, and southern ward along with Al-Ain, and Dubai highways (Figure 5).

In 2020, the spread of COVID-19 pandemic and the collapse of oil prices had a severe effect on both the population and the urban growth not only in Abu Dhabi city, but also across several GCC oil exporting countries. These have resulted in a negative impact on investment in many publicly funded development projects where budget cuts have been instituted or projects have even been frozen. These difficult circumstances have had a profound impact on contractor's abilities and skills to keep the workforce fully mobilized and able to make progress with the work on site. Also, these harsh conditions had an impact on a large number of people working in the service sector and rely on this sector for earning their living in jobs in hospitality, tourism, entertainment, logistics, property and retail. Many of Abu Dhabi's hotels and restaurants are internationally acclaimed, but now nearly half the restaurants and hotels are expected to go out of business in the next few months alone 


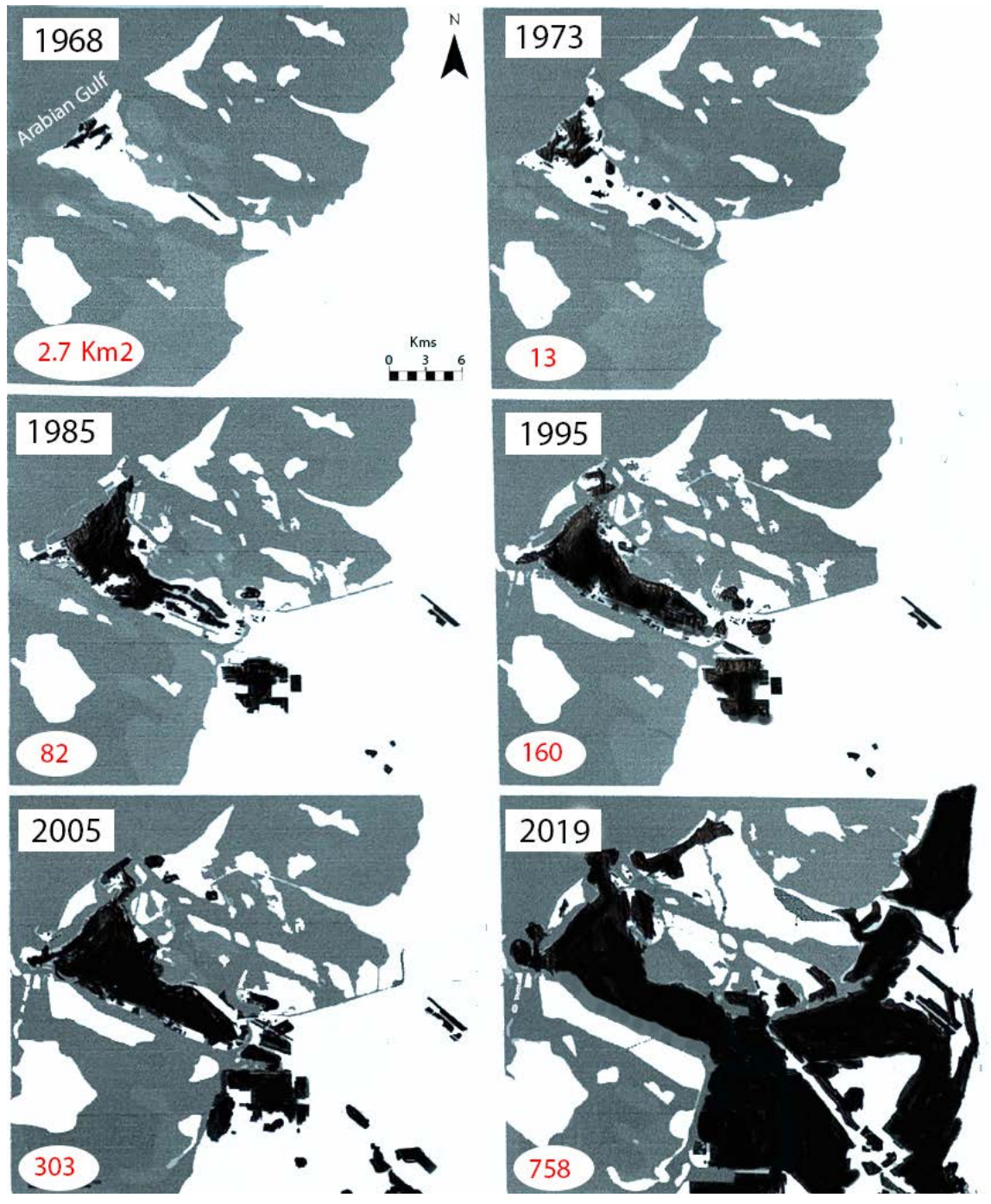

Figure 5. Stages of urban sprawl of Abu Dhabi city 1968-2019. Source: Modification after (Bani Hashim, 2016).

For a country that relies on a $90 \%$ expatriate population for much of its economic activity, the stakes are even higher: if residents can no longer find work. They are likely to return to their home countries of origin. Job losses and salary cuts as a result of the economic downturn will result in subdued demand for properties from local buyers. Also travel restrictions will reduce international demand. In fact, the economic contraction and its fiscal implications will be most acute and will have a severe effect on the growth of the population as well as the urban growth of the city in the near future.

\section{Conclusion}

Abu Dhabi city, the capital of the United Arab Emirates is a good example of a rapidly developing city. Abu Dhabi and other Arabian Gulf cities have evolved tremendously since the second half of 20th century, due to investment of oil and gas revenues from 1975 till present time. The city's population increased from 
nearly 100,000 in 1975 to more than 1.3 million inhabitants in 2019. The abnormal population growth has been achieved by attracting large numbers of foreign guest workers from many countries, mostly from Asia. The inflow of expatriates has played a significant role in changing the population size and the urban built-up area which has expanded enormously. The rapid development of the city transforms Abu Dhabi from a small poor village into a global business, financial and leisure hub. During the last two decades, Abu Dhabi city's built-up area expanded like never before due to economic growth and investment level acceleration. Development projects were planned to support the expansion of the city, thus transforming deserts into a city of the future. The total built-up area increased from only 13 square kilometres in 1973 to 758 square kilometres in 2019, as Abu Dhabi's area increased almost $5000 \%$ in only 45 years. This renders Abu Dhabi one of the fastest-growing cities in the world.

The urban sprawl of Abu Dhabi city is generally distinguished by two main regions; the island which has the earliest developments, and the mainland which has seen multiple new extensions created since the 1970's. The island jutting out into the Arabian Gulf has created a natural limit for the horizontal growth of the city, and increasing number of high-rise buildings. This has contributed to a continuous increase of population density in the island, and resulted in obtaining compact communities which favored closeness and diversity. However, moving outside the island, to the South, a horizontal low-density sprawl started to consume the mainland. The expansion carried along changes in the urban form and the general perception of the city. Leapfrogging developments have generously emerged in the mainland, consisting of mainly residential land use and a very low-density population. The city is known in the region today for its greenery; the former desert strip today includes numerous parks and gardens.

This changing urban form in combination with the hot and arid climate of the area has contributed to bringing the city to one of the highest per capita ecological footprints. In brief, Abu Dhabi has undergone significant abnormal urban changes and great population growth over the past five decades, which has transformed it from a small desert village to a global business and tourism hub and economic centre.

\section{Conflicts of Interest}

The author declares no conflicts of interest regarding the publication of this paper.

\section{References}

Abu Dhabi Hotel Performance Report (2019). https://tcaabudhabi.ae/DataFolder/reports/hotel-establishment/2019/Q4-and-2019-Hot el-Report-English.pdf

Abu Dhabi Municipality (ADM) (1996). Abu Dhabi: Dana of the Gulf, Planning and Urban Development (Studies and Research Section). Dubai: Abu Dhabi Municipality \& Town Planning Department. 
Abu Dhabi Municipality (ADM) (2003) Abu Dhabi: Dana of the Gulf, Planning and Urban Development, Studies and Research Section. Abu Dhabi: Abu Dhabi Municipality.

Abu Dhabi Statistics Centre, SCAD (2016). Key Indicators. https://www.scad.ae/en/pages/default.aspx

Abu Dhabi Statistics Centre, SCAD (2020). https://www.scad.gov.ae/Release\%20Documents/Statistical\%20Yearbook\%20of\%20Ab u\%20Dhabi 2020 Annual Yearly en.pdf

Al Fahim, M. (1995). From Rags to Riches: A Story of Abu Dhabi. London: The London Center of Arab Studies.

Alawadi A, K., \& Benkraouda O. (2017). What Happened to Abu Dhabi's Urbanism? The Question of Regional Integration. Journal of Urban Design, 23, 367-394. https://doi.org/10.1080/13574809.2017.1361786

Allawi, H. (2017). Phases of Development: A Cultural, Societal and Environmental Overview of Abu Dhabi's Urban Morphology. Journal of Engineering Technology, 4, 45.

Bani Hashim, A. (2015). Planning Abu Dhabi: From Arish Village to a Global, Sustainable, Arab Capital City. Unpublished Doctor of Philosophy Dissertation, Berkeley, CA: University of California.

Bani Hashim, A. (2016.) The History of Planning Residential Neighbourhoods in Abu Dhabi. In Y. Elsheshtawy (Ed.), Transformation: The Emirati National Housing (pp. 58-77). Venice: La Biennale di Venezia.

Davidson, C. (2007) The Emirates of Abu Dhabi and Dubai: Contrasting Roles in the International System. Asian Affairs, 38, 33-48. https://doi.org/10.1080/03068370601108624

Dempsey, M. (2014). Castles in the Sand: A City Planner in Abu Dhabi. Jefferson, NC: Mc Farland.

Elessawy, F. (2014). Living in the Move: Impact of Guest workers on Population Characteristics of the United Arab Emirates. The Arab World Geographer, 17, 2-23.

Elessawy, F. (2020). The Consequences of Population Growth on the Demographic Characteristics of Abu Dhabi City in the United Arab Emirates. Advances in Economics and Business, 8, 268-276. https://doi.org/10.13189/aeb.2020.080502

Elsheshtawy, Y. (2008). Cities of Sand and Fog: Abu Dhabi's Global Ambitions. In Y. Elsheshtawy (Ed.), The Evolving Arab City: Tradition, Modernity and Urban Development (pp. 258-304). London: Routledge.

Elsheshtawy, Y. (2016). Transformation: The Emirati National Housing. Pavilion of the $U A E$ at the 15th Venice Architecture Exhibition, Venice, 28 May-27 November 2016, 5.

Federico, C. (2015) Eco-Cities and the Transition to Low Carbon Economies. London: Palgrave Macmillan.

Ghazal, R. (2013). The Man behind Abu Dhabi's Master Plan. The National, November 11.

https://www.thenationalnews.com/uae/the-man-behind-abu-dhabi-s-master-plan-1.64 $\underline{8363}$

Hume, J. (2008). Tales of the City. https://www.google.com/search?q=Hume,+Jessica+(2008).+\%E2\%80\%9CTales+of +the + city, $\% \mathrm{E} 2 \% 80 \% 9 \mathrm{D}+\mathrm{The}+$ National,+Daily+Newspaper,+June+4. $8 \mathrm{rlz}=1 \mathrm{C} 1 \mathrm{GCEU}$ enA E894AE894\&tbm $=$ isch\&source $=$ iu\&ictx $=1 \&$ fir

Lieto, L. (2019). Planning for the Hybrid Gulf City. In: H. Molotch, \& D. Ponzini (Ed.), The New Arab Urban: Gulf Cities of Wealth, Ambition and Distress (pp.130-146). New York, NY: New York University Press. 
Maitra, J., \& Al-Hajji, A. (2001). Qasr Al Hosn: The History of the Rulers of Abu Dhabi 1793-1966. Abu Dhabi: Centre for Documentation and Research.

Makhlouf, A. (2006). Origin \& Development of Abu Dhabi City 1761, 1961, 2004. Abu Dhabi Municipality, Urban Planning Department. Unpublished Report.

Mtapuri, O., \& Giampiccoli, A. (2017) Abu Dhabi and Doha: Skyscraping for Tourism Development. The Arab World Geographer/Le Géographe du monde arabe, 20, 42-66.

Numbeo (2020). Crime in Abu Dhabi, United Arab Emirates. https://www.numbeo.com/crime/in/Abu-Dhabi

Othman, A. (2006). Urbanism and Town Planning: Observations on the Development of Abu Dhabi. In D. Salma Samar (Ed.), The Architecture of the United Arab Emirates (pp. 102-119). Reading: Garnett Publishing Ltd.

Salloum, H. (1997). How Sheikh Zayed Turned the Desert Green. The Christian Science Monitor. https://www.csmonitor.com/1997/0527/052797.opin.opin.1.html

Skyscraper Center. Com (n.d.). Abu Dhabi.

https://www.skyscrapercenter.com/city/abu-dhabi

United Nations Population Division (2019) World Urbanization Prospects 2018. https://population.un.org/wup/Publications/Files/WUP2018-Highlights.pdf 